\title{
Define of internal recirculation coefficient for biological wastewater treatment in anoxic and aerobic bioreactors
}

\author{
Volodymyr Rossinskyi ${ }^{1, *}$ \\ ${ }^{1}$ Department of Ecobiotechnology and Bioenergy, National Technical University of Ukraine «Kyiv \\ Polytechnic Institute», 37, Prospect Peremohy, 03056, Kyiv-56, Ukraine
}

\begin{abstract}
The biological wastewater treatment technologies in anoxic and aerobic bioreactors with recycle of sludge mixture are used for the effective removal of organic compounds from wastewater. The change rate of sludge mixture recirculation between bioreactors leads to a change and redistribution of concentrations of organic compounds in sludge mixture in bioreactors and change hydrodynamic regimes in bioreactors. Determination of the coefficient of internal recirculation of sludge mixture between bioreactors is important for the choice of technological parameters of biological treatment (wastewater treatment duration in anoxic and aerobic bioreactors, flow capacity of recirculation pumps). Determination of the coefficient of internal recirculation of sludge mixture requires integrated consideration of hydrodynamic parameter (flow rate), kinetic parameter (rate of oxidation of organic compounds) and physical-chemical parameter of wastewater (concentration of organic compounds). The conducted numerical experiment from the proposed mathematical equations allowed to obtain analytical dependences of the coefficient of internal recirculation sludge mixture between bioreactors on the concentration of organic compounds in wastewater, the duration of wastewater treatment in bioreactors.
\end{abstract}

\section{Introduction}

The biological oxygen demands $\left(\mathrm{BOD}_{5}\right)$ in municipal wastewater usually are 100$300 \mathrm{mgO}_{2} / \mathrm{l}$. The municipal wastewater usually contains suspended solids $147.3-468.2 \mathrm{mg} / \mathrm{l}$, phosphor compounds 0.2-15.8 mg/l, nitrogen compounds $13.2-63.7 \mathrm{mg} / \mathrm{l}$, synthetic detergents $8-25 \mathrm{mg} / 1[1,2]$.

Synthetic detergents as amphiphilic xenobiotics, have a negative impact on the process of oxidation of organic compounds in units for biological wastewater treatment through localization substrate, dispersing the sludge, breach of oxygen regime and inhibition of

* Corresponding author: wrossin@live.com 
activated sludge microorganism activity [3]. The synthetic surfactants with membranotropic properties affect microorganisms $[4,5]$.

The anoxic and aerobic biological treatment technology is mainly used for the effective removal of organic compounds and nutrients from municipal wastewater [6].

The assessment oxidation velocity (kinetic parameters) of organic compounds in aerobic and anoxic bioreactors with activated sludge depending on the initial concentration of organic contaminants is carried out by Monod equation [6-8].

To ensure denitrify bacteria the necessary substrate, nitrates and nitrites, treatment of wastewater is carry out in anoxic bioreactors with organizing recycle of sludge mixture from aerobic bioreactors.

The rate of internal recirculation of sludge mixture between anoxic and aerobic bioreactors is $50-500 \%$ [9]. Biological process of wastewater treatment operate with internal recycle of $200 \%$ [10]. The change rate of internal recycle of sludge mixture between the aerobic and anoxic bioreactor leads to a redistribution of the concentration of dissolved organic compounds in wastewater and change hydrodynamic regimes in bioreactors.

The effect of internal recirculation of sludge mixture between aerobic and anoxic bioreactors on efficiency of wastewater treatment from organic compounds is an important scientific issue for choice technological parameters of biological wastewater treatment.

\section{Materials and methods}

The experimental research of define internal recirculation coefficient was conducted for wastewater treatment from organic compounds in anoxic and aerobic bioreactors (Fig. 1).

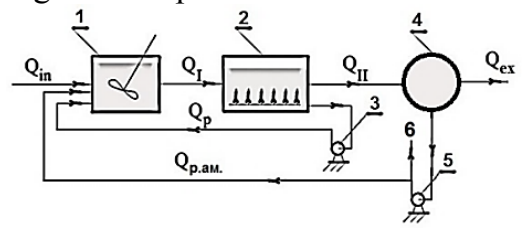

Fig. 1. Scheme of biological wastewater treatment in anoxic and aerobic bioreactors: 1 - anoxic bioreactor; 2 - aerobic bioreactor; 3 - recirculation pump; 4 - secondary clarifier; 5 - recirculation pump of activated sludge; 6 - disposal of excess activated sludge; Qin - inlet wastewater flow to anoxic bioreactor; $\mathrm{Q}_{\mathrm{I}}$ - outlet wastewater flow from anoxic bioreacor; $\mathrm{Q}_{\mathrm{II}}$ - wastewater flow from aerobic bioreactor to secondary clarifier; Qp - internal recirculation flow (nitrate recycle); $\mathrm{Q}_{\mathrm{p} . \mathrm{am} .}-$ recirculation flow of activated sludge; $\mathrm{Q}_{\mathrm{ex}}-$ flow of treated wastewater.

Internal recirculation flow capacity $\left(\mathrm{Q}_{\mathrm{p}}, \mathrm{m}^{3} /\right.$ hour $)$ can be defined:

$$
\mathrm{Q}_{\mathrm{p}}=\mathrm{n}_{\mathrm{H}} \cdot \mathrm{Q}_{\text {in }}
$$

where $n_{H}$ is a coefficient of internal recycle of sludge mixture, unit fractions.

Considering that the oxidation of organic compounds in anoxic bioreactors perform facultative bacteria using oxygen of nitrites and nitrates, the concentration of organic compounds in sludge mixture after anoxic bioreactor can be defined:

$$
C_{I}^{e x}=C_{I}^{i n}-\left[t_{I}\left(0, t_{i}^{I}\right)\right] \cdot d C_{I} / d t
$$

where $C_{I}$ is concentration of organic compounds in sludge mixture in anoxic bioreactor, $\mathrm{mgBOD}_{\text {total }} / \mathrm{l}$; $t_{I}$ is a duration of wastewater treatment in the anoxic bioreactor, hour.

It is obvious that concentration of organic contaminants in sludge mixture at the outlet of the anoxic bioreactor $\left(C_{I}^{e x}, \operatorname{mgBOD}_{\text {total }} / \mathrm{l}\right)$ numerically equal to the concentration of 
organic contaminants in sludge mixture inlet the aerobic bioreactor $\left(C_{I I}^{\text {in }}, \operatorname{mgBOD}_{\text {total }} / 1\right)$ (Fig. 1).

The oxidation of organic compounds carried by aerobic microorganisms in the aerobic bioreactors, so the concentration of organic contaminants in sludge mixture after aerobic bioreactor can be expressed:

$$
C_{I I}^{e x}=C_{I I}^{\text {in }}-\left[t_{I I}\left(0, t_{i}^{I I}\right)\right] \cdot d C_{I I} / d t
$$

where $C_{I I}$ is concentration of organic compounds in sludge mixture in aerobic bioreactor, $\mathrm{mgBOD}_{\text {total }} / 1 ; t_{I I}$ is a duration of wastewater treatment in the aerobic bioreactor, hour.

The renovation existing aerotanks by releasing some useful volume of aerotanks under anoxic bioreactor duration ( $t_{I}$, hour) of wastewater treatment in anoxic bioreactor without nitrate recycle can be defined:

where $W_{I}$ is useful volume of anoxic bioreactor, $\mathrm{m}^{3}$.

$$
t_{I}=W_{I} / Q_{\text {in }}
$$

The duration of wastewater treatment ( $t_{t}^{p}$, hour) in the anoxic bioreactor can be expressed given the internal recirculation flow:

$$
t_{I}^{p}=W_{I} /\left(Q_{\text {in }}+Q_{p}\right)
$$

where $Q_{p}$ is internal recirculation flow capacity, $\mathrm{m}^{3} /$ hour.

The velocity of passing an elementary volume of sludge mixture in the anoxic bioreactor can be defined considering changing of internal recirculation flow capacity:

$$
\theta_{I}=t_{I}^{p} / t_{I}=1 /\left(1+n_{r}\right)
$$

The balance equations system for determinate of organic compounds concentration change by phased wastewater treatment in anoxic and aerobic bioreactors with internal recirculation of sludge mixture considering activated sludge recirculation from secondary clarifier can be presented:

$$
\left\{\begin{array}{l}
n_{H}=Q_{p} / Q_{i n} ; \quad C_{I}^{i n}=\frac{C_{m i x}+n_{H} \cdot C_{p}}{\left(1+n_{H}\right)} ; \quad C_{m i x}=\frac{C_{i n}+C_{e x} \cdot R}{1+R} ; R=\frac{a_{i}}{\frac{1000}{J_{i}}-a_{i}} ; \\
C_{I}^{e x}=C_{I}^{i n}-\frac{1}{\left(1+n_{H}\right)} \cdot \frac{d C_{I}}{d t} \cdot t_{I}\left(0, t_{i}^{I}\right) ; \quad C_{I I}^{i n}=C_{I}^{e x} ; C_{I I}^{e x}=C_{I I}^{i n}-\frac{1}{\left(1+n_{H}\right)} \cdot \frac{d C_{I I}}{d t} \cdot t_{I I}\left(0, t_{i}^{I I}\right)
\end{array}\right.
$$

where $C_{i n}$ is a inlet concentration of organic compounds to anoxic bioreactor, $\operatorname{mgBOD} / \mathrm{l} ; C_{e x}-$ concentration of organic compounds in treated wastewater, $\mathrm{mgBOD} / \mathrm{l} ; C_{p}$ - concentration of organic compounds in internal recirculation flow, $\mathrm{mgBOD} / \mathrm{l} ; C_{m i x}-$ concentration of organic compounds in mixture of activated sludge and wastewater, $\mathrm{mgBOD} / 1 ; n_{H}-$ internal recirculation coefficient, fraction of $1 ; C_{I}$ - concentration of organic compounds in anoxic bioreactor, $\mathrm{mgBOD} / 1 ; t_{I}$ - duration of wastewater treatment in anoxic bioreactor, hour; $C_{I I}$ - concentration of organic compounds in sludge mixture in aerobic bioreactor, $\mathrm{mgBOD} / \mathrm{l} ; t_{I I}-$ duration of wastewater treatment in aerobic bioreactor, hour; $J_{i}$ - index of activated sludge, $\mathrm{cm}^{3} / \mathrm{g} ; R$ - coefficient of activated sludge recirculation, unit fractions.

The complex computational experiment for definition of internal recirculation coefficient was conducted for wastewater containing biodegradable organic compounds with concentration $C_{i n}=300 \mathrm{mgBOD} / 1$ by dose of activated sludge $a_{i}=2 \mathrm{~g} / \mathrm{l}$, dissolved oxygen concentration in anoxic bioreactor $0.1 \mathrm{mg} / \mathrm{l}$, dissolved oxygen concentration in aerobic 
bioreactor $2 \mathrm{mg} / \mathrm{l}$, concentration of nitrate $5 \mathrm{mgN}^{-N_{3}}{ }^{-1} / 1$, index of activated sludge $80 \mathrm{~cm}^{3} / \mathrm{g}$.

\section{Results and discussions}

Decrease of concentration of organic compounds from $300 \mathrm{mgBOD} / 1$ to $15 \mathrm{mgBOD} / 1$ with treatment duration of wastewater in anoxic bioreactor 0.5 hours and aerobic bioreactor 3 hours is provided with a coefficient of internal recirculation of sludge mixture of $180 \%$ (Fig. 2). Reduced treatment time in the aerobic bioreactor up to 1.5 hours needs an increase the coefficient of internal recirculation to $420 \%$. An increase in the coefficient of internal recirculation can reduce the useful volume of the aerobic bioreactor, but requires the selection of a more productive recirculation pump.

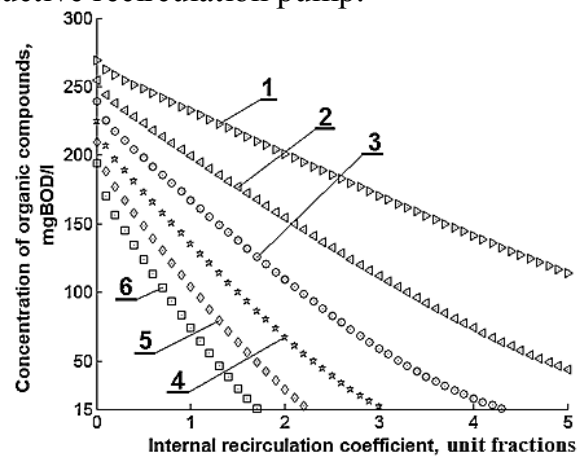

Fig. 2. Dependences of the concentration of biodegradable organic compounds $\left(\mathrm{BOD}_{\text {total }}\right)$ from internal recirculation coefficient and duration of wastewater treatment in anoxic ( 0.5 hour) and aerobic bioreactors (hour): $1-0,5 ; 2-1 ; 3-1,5 ; 4-2 ; 5-2,5 ; 6-3$.

The rate of organic compounds removal also depends on the wastewater treatment duration in anoxic condition. For decrease of concentration of organic compounds from $300 \mathrm{mgBOD} / 1$ to $15 \mathrm{mgBOD} / 1$ with wastewater treatment duration in anoxic bioreactor 0.5 hours and aerobic bioreactor 2 hours is provided with a coefficient of internal recirculation of sludge mixture of $380 \%$ (Fig. 3). The reduced treatment time in the anoxic bioreactor up to 1 hours needs an increase the coefficient of internal recirculation to $340 \%$ for treatment time in the aerobic bioreactor is 2 hours.

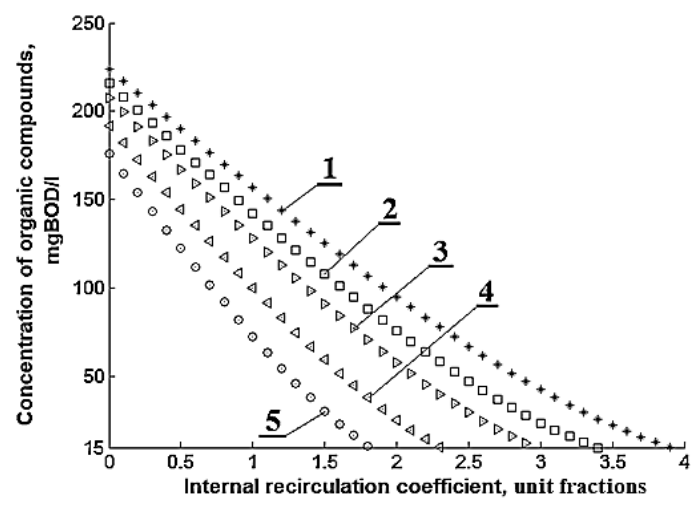

Fig. 3. Dependences of the concentration of biodegradable organic compounds $\left(\mathrm{BOD}_{\text {total }}\right)$ from internal recirculation coefficient and duration of wastewater treatment in aerobic ( 2 hour) and anoxic bioreactors (hour): $1-0,5 ; 2-1 ; 3-1,5 ; 4-2$. 
The twice decreasing the duration of treatment of wastewater in aerobic bioreactors requires an increase in the coefficient of internal recirculation by $57 \%$. However, twice decreasing the duration of treatment of wastewater in anoxic bioreactors requires an increase in the internal recirculation coefficient to $10 \%$. Regulation of useful volumes of bioreactors enables to minimize electricity consumption for recycling sludge mixture.

The synthetic detergents inhibit the processes of oxidation of organic compounds in anoxic and aerobic bioreactors. The assess a rate of removal of organic compounds carried by the numerical experiment for the nitrate concentration in sludge mixture $5 \mathrm{mgN}-\mathrm{NO}_{3}{ }^{-1} / 1$ and change the concentration of synthetic detergents in the wastewater from 0 to $20 \mathrm{mg} / \mathrm{l}$. The semi-saturation constant for synthetic detergents was adopted $30 \mathrm{mg} / 1$ [11].

For decrease of concentration of organic compounds from $300 \mathrm{mgBOD} / 1$ to $15 \mathrm{mgBOD} / 1$ with treatment duration of wastewater duration of wastewater treatment in anoxic bioreactor 0.5 hour and aerobic bioreactor 2 hour and without synthetic detergents is provided with a coefficient of internal recirculation of sludge mixture of $380 \%$. Decrease of concentration of organic compounds from $300 \mathrm{mgBOD} / 1$ to $15 \mathrm{mgBOD} / 1$ with treatment duration of wastewater duration of wastewater treatment in anoxic bioreactor 0.5 hour and aerobic bioreactor 2 hour is provided with a coefficient of internal recirculation of sludge mixture of $500 \%$ for wastewater contains synthetic detergents with concentration of $5 \mathrm{mg} / \mathrm{l}$ (Fig. 4). The increasing concentrations of synthetic detergents from 0 to $10 \mathrm{mg} / \mathrm{l}$ needs to increase the coefficient of the internal recirculation coefficient to $45 \%$.

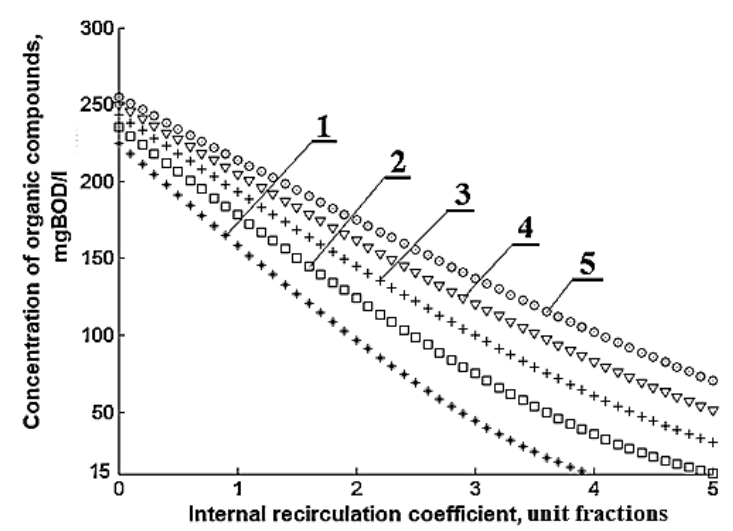

Fig. 4. Dependences of the concentration of biodegradable organic compounds $\left(\mathrm{BOD}_{\text {total }}\right)$ from internal recirculation coefficient, duration of wastewater treatment in anoxic ( 0.5 hour) and aerobic bioreactors ( 2 hour) and concentration of synthetic detergents in sludge mixture $(\mathrm{mg} / \mathrm{l}): 1-0 ; 2-5$; $3-10 ; 4-15 ; 5-20$.

\section{Conclusion}

The internal recirculation coefficient for biological wastewater treatment in anoxic and aerobic bioreactors is important for choosing the exploitation of technological parameters of bioreactors with recirculation of sludge mixture.

Although for biological wastewater treatment it is recommended to take internal recirculation coefficient of 50-500\% [9] and 200\% [10], define of internal recirculation coefficient can be determined by iterative computation by the balance equations system (7). The increase the efficiency of biological wastewater treatment from organic compounds achieved through the increase of the internal recirculation coefficient considering inhibition biological treatment processes by synthetic detergents in bioreactors with different oxygen conditions. 
The full assessment of wastewater treatment of organic compounds in bioreactors with different oxygen conditions along with the internal recirculation rate requires consideration of the recirculation rate of activated sludge from the secondary clarifier.

\section{References}

1. M. H. Gerardi, Wastewater Bacteria (2006)

2. O. Vasylenko, O. Polishchuk, L. Vasylenko, Ecological safety and Environmental Sciences, 15 (2014)

3. V. Rossinskyi, Bulletin of National University of Water Management and Nature Resources Use, 3 (2016)

4. S. A. Ostroumov, Biological Effects of Surfactants (CRC Press. Taylor \& Francis. Boca Raton, 2006)

5. A. Dereszewska, S. Cytawa, R. Tomczak-Wandzel, K. Medrzycka Pol. J. Environ. Stud. 24, (2015)

6. M. Henze, C. P. L. Grady, W. Gujer, G. V. R. Marais, T. Matsuo, Activated Sludge Model No. 1. (London, 1987)

7. V. M. Rossinskyi, L. A. Sablii, Issues of Water Supply, Water Disposal and Hydraulics, 27 (2016)

8. O. J. Oliynyk, T. S. Hayrapetyan, Reports of the National Academy of Sciences of Ukraine, 5 (2015)

9. M. Henze et al., Wastewater Treatment: Biological and Chemical Processes (Springer: Berlin, Heidelberg, 2013)

10. T. Yoona, H. Lee, C. Kima. Journal of Membrane Science, 242 (2004)

11. V. M. Rossinskyi, L. A. Sablii, The 8th Eastern European Young Water Professionals Conference : Leaving the Ivory Tower Bridging the Gap between Academia, Industry, Services and Public Sector (Oficyna Wydawnicza Politechniki Wrocławskiej, 2016) 